Yi-wen Zhu, Harald Bathelt* and Gang Zeng

\title{
Learning in Context: A Structural Equation Modeling Approach to Analyze Knowledge Acquisition at Trade Fairs
}

https://doi.org/10.1515/zfw-2020-0006

Received: 28 February 2020; accepted 12 May 2020

Abstract: Conceptualizations of trade fairs as temporary clusters have identified important learning processes at such events, particularly at leading international trade fairs - both in developed and developing countries. However, little attention has been paid to the home contexts of participating firms that may affect knowledge acquisition patterns. In particular, it is unclear which contextual factors may influence learning behavior. This paper aims to investigate the role of geographical context conditions at the exhibitors' permanent locations and whether their knowledge acquisition behavior during trade fairs varies systematically with aspects, such as city scale, peripherality, growth dynamics and connectivity. Our analysis is based on a survey of 211 firms conducted between 2014 and 2018 at the China International Industry Fair (CIIF) in Shanghai - one of Asia's most important manufacturing fairs. Using structural equation modeling (SEM), the study identifies significant pathways of knowledge acquisition and how these differ with geographical context.

Keywords: China; geographical context; knowledge acquisition; structural equation modeling (SEM); trade fairs

JEL Codes: C30, D83, R12

\section{Introduction}

In the literature, trade fairs have been conceptualized as temporary clusters, characterized by intensive knowledge transfer and circulation processes that occur over a period

\footnotetext{
*Corresponding author: Prof. Harald Bathelt, University of Toronto, Department of Geography \& Planning, 100 St. George St., M5S 3G3 Toronto, Ontario, Canada, e-mail: harald.bathelt@utoronto.ca Prof. Yi-wen Zhu, East China Normal University, The Center for Modern Chinese City Studies, 3663 North Zhongshan Road, 200062 Shanghai, China, e-mail: ywzhu@geo.ecnu.edu.cn Prof. Gang Zeng, East China Normal University, The Center for Modern Chinese City Studies, 3663 North Zhongshan Road, 200062 Shanghai, China, e-mail: gzeng@re.ecnu.edu.cn
}

of a few days (Maskell et al., 2006). Exhibiting firms do not just present products to their markets and engage with current and future buyers, they also use these events to get feedback about their products and learn about new technologies and market trends (Callon, 2017; Bathelt et al., 2017). Especially large international trade fairs that bring together actors from many cities and regions in different countries, with different economic contexts and specializations, establish an important channel for firms to engage in trans-local learning, knowledge sharing and knowledge acquisition. This has been shown both for events in developed (Schuldt/Bathelt, 2011) and developing economies (Luo/Zhong, 2016; Zhong/Luo, 2018).

At the same time, there is no doubt that the capabilities of firms to learn and acquire knowledge differ widely between cities and regions and, partially because of this, spatial inequalities have attracted increasing attention in economic geography in recent years (Dannenberg et al., 2018). The heterogeneity of geographical context conditions (while also relevant in developed economies) is especially strong in developing economies, such as China (Veeck et al., 2016; Li et al., 2020), where significant differences in economic development and innovation capability can be found between eastern, central and western regions (Wang/Zeng, 2017). For example, per capita GDP in 2016 was only US-\$4,800 and US-\$5,500 in Yunnan Province and Sichuan Province in western China, respectively, while Shanghai had a value three times as high, at US- $\$ 18,000$.

It has been suggested that geographical context is an important influence on the ability of firms to acquire, absorb and transform knowledge (Storper, 2009; Bathelt/ Glückler, 2011). For instance, firms in remote areas with a poor knowledge base may have few opportunities to acquire relevant knowledge through local communication channels and may not be able to fully utilize that knowledge, while firms in leading industrial agglomerations have manifold options to constantly exchange sophisticated knowledge with near and distant partners and have developed skill-sets to do this effectively.

One could therefore hypothesize that geographical inequalities have the potential to impact knowledge acqui- 
sition and creation processes at trade fairs, even though we currently have little knowledge about this. Comparing different types of trade fairs in Asia, Li (2014; 2015) suggested that countries/regions will not benefit equally from leading technology events if local firms in a developing context do not have the capability to understand and absorb related knowledge. While firm-specific differences certainly play a crucial role, we may find that firms from certain cities and regions have more experience and are better equipped to exploit the unique knowledge ecologies at leading international trade fairs to produce innovations and generate a competitive advantage. It is in this context that we propose a research agenda to explore knowledge acquisition behavior and learning processes of exhibiting firms at trade fairs. The goals of this paper are twofold: First, we aim to identify important knowledge acquisition pathways at trade fairs, focusing on the exhibiting firms. Second, our goal is to investigate whether and how these pathways are shaped by the geographical context conditions at the firms' home base.

To conduct this analysis, we employ structural equation modeling (SEM) - a method from behavioral and social science research - to contribute to "building better methods in economic geography" (Bathelt/Li, 2020). SEM allows us to use survey information to quantify latent variables that cannot be measured directly, such as knowledge acquisition behavior, and to distinguish between significant and insignificant relationships (pathways) between these variables (Hox/Bechger, 1998). In a second step, we use multi-group SEM to analyze how these pathways are affected by geographical context conditions as moderating variables. We conduct this analysis based on a survey of 211 firms conducted between 2014 and 2018 at the China International Industry Fair (CIIF) in Shanghai - one of Asia's most important manufacturing fairs. In this relatively homogenous organizational field, we conclude that many knowledge acquisition pathways are not strongly affected by geographical context factors, such as city scale, peripherality, growth dynamics or connectivity. However, we also find that firms from larger, more developed and better-connected cities have the strongest capability to engage in and learn from intensive face-to-face communication, while firms from smaller, less developed and lesser connected cities engage more actively in observation processes, characterized by knowledge flows that are less rich and less clear.

Our analysis is structured as follows: Section 2 presents the conceptual background of the paper and develops key ideas on knowledge acquisition pathways and how they differ according to the geographical context of exhibitors at trade fairs. Section 3 discusses the statistical proce- dure of structural equation modeling (SEM) while section 4 explains the case study, questionnaire and survey design and the variable selection process. Section 5 presents the results of the empirical analysis on knowledge acquisition pathways at trade fairs and their variation, and section 6 draws conclusions and policy implications.

\section{Conceptual Background}

\subsection{Trade Fairs and Knowledge Acquisition}

The development of the knowledge economy has fundamentally changed our understanding of economic development, and due to advances in communication and transportation technologies it has become much easier to access remote knowledge (Henn/Bathelt, 2015). Still, localized and decentralized knowledge generation continues to play a fundamental role in economic processes (Amin/ Cohendet, 2004) and there is no indication that this may change. While traditional research on trade fairs focused on their role for industrial marketing and stimulating trade (Kirchgeorg et al., 2003), the literature on international trade fairs as temporary clusters (Maskell et al., 2006) and the development of a knowledge-based conceptualization of trade fairs (Li/Bathelt, 2017) has shown that these events have a much broader significance. They are crucial places that enable processes of knowledge sharing and circulation, sense-making, learning, relationship-building and the reproduction of institutional arrangements. This shift towards understanding the role of trade fairs is also visible in the Chinese context. Early research on Chinese trade fairs emphasized their role in promoting import and export activities (Jin et al., 2010) and suggested that nontrade objectives, such as promoting industrial innovation, are less important at these events (Kay, 2005). More recent work, however, has shown that the leading events in the country are not fundamentally different from those in Western Europe or North America and can also be viewed as temporary clusters (Bathelt/Zeng, 2014) that enable important knowledge generation and learning processes (Shan et al., 2014; Luo/Zhong, 2016; Bathelt et al., 2017; Zhong/Luo, 2018). For instance, some studies have shown that trade fair interaction can have a stimulating impact on innovation knowledge networks (Zhu/Zeng, 2017; Zhu et al., 2020).

As such, there is plenty of evidence that trade fairs, while having different functions and serving different purposes, are important places for knowledge transfers, generation and learning, both in developed and developing economies. Events of nation-wide or international signifi- 
cance provide an opportunity for firms to meet and interact in a highly-condensed form over a few days, often in an annual or biannual rhythm. Such events provide an opportunity for members of an organizational field (DiMaggio/ Powell, 1983) to get together to present established products and recent developments, and to exchange views on current and future industry trends (Schuldt/Bathelt, 2011). Among the actors that come together are manufacturers, traders, suppliers, users, technology experts, media and other relevant experts from related industries. Therefore, from the perspective of trade fair exhibitors, which this paper focuses on, different actors are of interest in acquiring new knowledge about the field. We consider three types of actors in this study. First, from a value chain perspective, customers are vertically linked with the exhibiting firms. Their knowledge base provides complementary insights and is highly relevant for the exhibitors' future business success. Second, competitors are horizontally linked with exhibiting firms and generally have similar knowledge bases. Because of their competitive position, they try to restrict knowledge spillovers to other firms at a similar stage of the value chain, yet they are interested in what these firms may know that differs from their own knowledge base. Knowledge exchanges with competitors are therefore of a different nature than those with customers (Maskell et al., 2006; Borghini et al., 2014). Third, partner firms may be horizontally or vertically linked to the exhibitors. As opposed to customers and competitors, where the existence or threat of a transaction context is central, ongoing social relationships in the manufacturing and/or research process are dominant in the case of partners. Again, the nature of interaction can be expected to differ as these partners already have detailed knowledge about each other's production context due to prior knowledge exchanges.

Depending on the goals, development stage, technological capability and strategy of the exhibitors, there are heterogeneous knowledge bodies that are of interest or relevance to them, which become the focus of interaction and learning at an event. In this research, we focus on three knowledge domains: (i) Knowledge about new customer requirements is of fundamental importance for the exhibitors, as it provides the basis for product adjustments and innovation to strengthen customer relations. (ii) New technological knowledge is equally important as it helps to improve and secure competitiveness when implemented in production (Zhu et al., 2020). (iii) Finally, general knowledge about new market trends can be effectively acquired at trade fairs, enabling exhibitors to align their existing production structure with general market dynamics (Li/Bathelt, 2017).
Because of the heterogeneity of actors at trade fairs and the different types of knowledge they need, different means are used to acquire this knowledge (Schuldt/ Bathelt, 2011). Clearly, knowledge acquisition and learning during trade fairs differs from long-distance communication modes such as telephone and internet, as exhibitors have the opportunity to engage in face-to-face conversations with other participants. While knowledge exchanges at trade fairs cannot be expected to be as deep as for instance with permanent partners in the home region, diverse interaction processes at these events enable important knowledge flows through face-to-face exchanges (Storper/Venables, 2004). Such interaction helps the participants understand complex knowledge, allows to ask for clarification and enables collective sense-making when discussing new developments with multiple actors (Song et al., 2007). A complementary knowledge creation process is enabled through learning-by-observation (Entwistle/Rocamora, 2006; Borghini et al., 2014). Since trade fairs are organized around showcasing products and technologies, these artefacts become the center of knowledge acquisition, as they can be observed or even touched, assessed and compared with other artefacts. At the same time, participants can obtain important additional information by observing other actors' facial expressions and gestures when talking to their peers or listening to their conversations (Walther et al., 2005). These observations help distinguish important from less important developments and collect ideas for innovation strategy development (Borghini et al., 2006).

The above discussion suggests that there are a variety of actors with which exhibiting firms at trade fairs can interact; there are different knowledge domains on which these interactions may focus; and exchanges can occur through different knowledge exchange processes. As shown in Figure 1 in the form of a simple conceptual diagram, this opens opportunities for different learning processes or multiple knowledge acquisition pathways at these events. For instance, exhibiting firms may engage in brief intense knowledge exchanges when customers or partners approach their booths, or they may observe their competitors' exhibits when wandering around the trade fair grounds. Face-to-face (F2F) conversation may target new or different specifications by customers, or may involve exchanges about new trends in major product markets. Similarly, observation processes may involve an inspection of new product technologies that are exhibited at the event. While all these pathways of knowledge acquisition may be possible, in reality firms use them more or less frequently. As will be discussed in the following section, related knowledge acquisition processes may also 


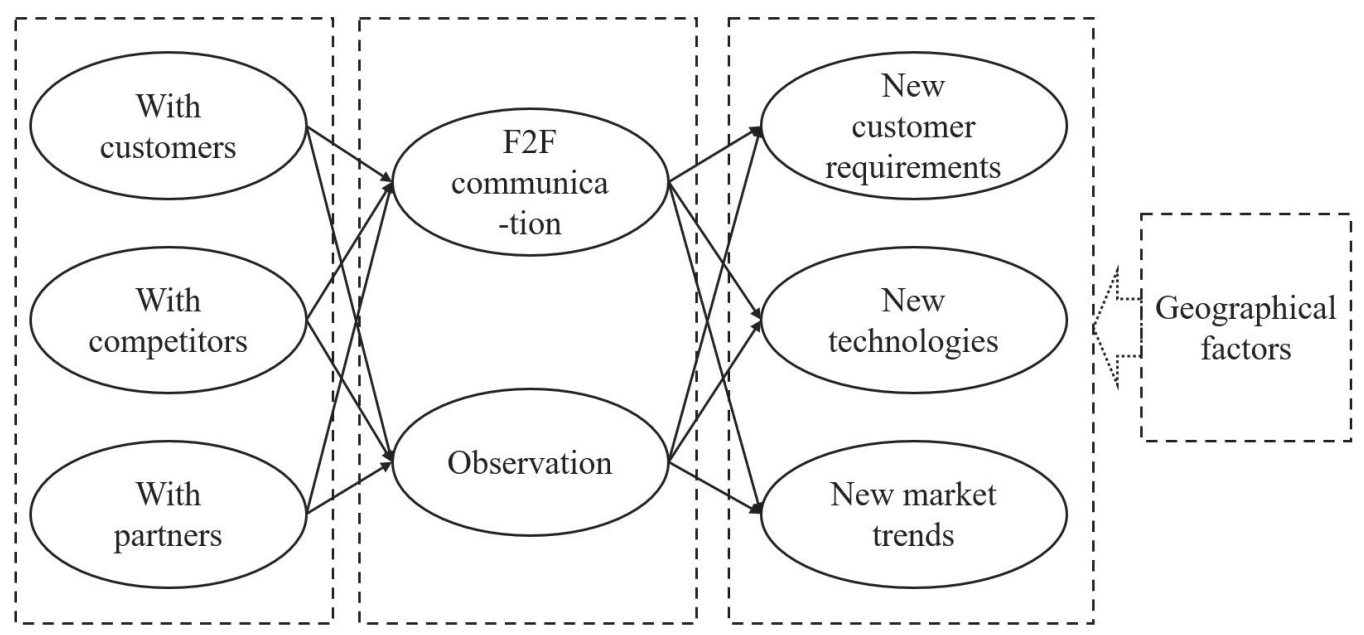

Figure 1: Conceptual Diagram - Potential Pathways of Knowledge Acquisition at Trade Fairs

depend on the context and capabilities of firms, and there may therefore be distinct differences in the ways how firms can use trade fairs to generate new knowledge.

\subsection{Knowledge Acquisition and Geographical Context}

While it may not be clear at the outset why firms from a specific city or region learn differently at trade fairs than others, it will be argued here that a firm's context conditions impact their learning behavior. Aside from geographical context conditions, there are of course also other factors that can impact knowledge acquisition patterns (Schuldt/Bathelt, 2011; Zhu/Zeng, 2017), such as technological capabilities and strategies of firms, the skill levels and experiences of participating individuals, or knowledge-building efforts of trade fair organizers. This paper will investigate the role of geographical context variables in particular, and analyze whether related influences operate as moderating variables through which firms apply knowledge acquisition pathways at trade fairs differently. We will use Structural Equation Modeling (SEM) to identify significant knowledge acquisition pathways and evaluate the impact of moderating variables on the use of these pathways during such events (Schumacker/ Lomax, 2016; Loehlin/Beaujean, 2017).

In the 'butterfly model' of trade fair types, Rinallo/ Golfetto (2011) distinguish trade shows according to their mix of international and national exhibitors and visitors, identifying four groups: local exchange events, import shows, export shows and international hub or flagship events. Depending on the type of trade fair, different knowledge exchange processes can be expected to domi- nate (Golfetto/Rinallo, 2015). For instance, export fairs are typically established around specialized industry agglomerations to support their market access. They are an ideal platform for exhibitors to learn about market trends and customer requirements in foreign markets. In comparison to export fairs, a local exchange fair may not be an ideal place to learn about global market trends or leading-edge technologies.

Learning opportunities are likely quite different if we consider the development stage of an economy (Li, 2014; 2015; Bathelt et al., 2015). For instance, firms from less developed cities or regions with a lack of technologically sophisticated industries may lack technological capabilities and therefore be unable to learn about latest technological developments at global hub events. As a result, the participation of many such firms may be a disincentive for technology leaders to participate in an event due to a lack of relevant learning opportunities. In an empirical study of the learning behavior at trade fairs, Bathelt/ Gibson (2015) suggest that these events operate similar to 'organized anarchies' in the sense that learning processes are often not deliberate and goal-oriented, but appear opportunistic and passive. Specifically, firms try to find applications in their production context for the novelties and problem solutions they come across during an event, rather than looking for distinct solutions to the problems or bottlenecks they face in their permanent locations. In a carefully designed study, Gibson (2018) showed that firms from differently-structured political economies perform different technological search processes at trade fairs, consistent with the conditions within which they operate in their home context. As such, we can assume that the ability to absorb and transform knowledge during a trade fair is related to the economic context within which a firm 
operates - and therefore that the institutional conditions, cultural influences and historical contexts of firms impact their learning opportunities at these events (Bathelt et al., 2015).

Arguably, knowledge acquisition is most effective if firms interact in an institutional, technological and cultural context that is similar to that in their home base (Henn, 2012). However, in a country with enormous spatial disparities, such as China, we can expect large differences in learning opportunities and capabilities, which are influenced by geographical context conditions. In this paper, we will investigate the impact of four contextual factors ${ }^{1}$ on knowledge acquisition and learning processes at trade fairs:

(i) Scale: If we assume that there is an association between the scale of an industrial agglomeration and the technological capability of its firms, then firms based in large industrial agglomerations will likely benefit more from knowledge spillovers and will be more experienced in learning-by-interaction to solve problems and generate innovations (van Oort et al., 2009; Storper et al., 2015). These firms may use opportunities for learning at trade fairs, especially through face-to-face interaction, more intensively than others.

(ii) Peripherality: In a similar way, firms in peripheral cities and regions may be less sophisticated and have a lower absorptive capacity (Cohen/Levinthal, 1990) and be less experienced than firms in core cities. While some may be dependent on trade fairs to acquire customers, others may be less aware of learning opportunities from other firms and may not recognize the importance of knowledge acquisition at these events or may not even participate as exhibitors.

(iii) Growth dynamics: Firms within a dynamic economic environment are aware of the importance to learn about new products and technological opportunities to be able to adapt quickly to changing market conditions. They may use learning-by-observation techniques to learn about successful innovations from their competitors, and use this knowledge to differentiate their production to gain a competitive advantage (Li, 2017). They can be expected to use similar learning techniques during trade fairs and attend these events to keep up with industry and technology dynamics.

(iv) Connectivity: Firms that are well-connected with partners in other cities and regions nationally and internationally are aware of the importance to connect with different

1 While these contextual factors differentiate distinct influences we should keep in mind that they can be interrelated to one another. knowledge and market contexts to stimulate innovation (Glückler, 2013). It can be expected that they have learned to successfully translate knowledge from one institutional setting into another. As such, they have likely developed advanced learning capabilities based on their face-to-face experiences with partner firms that may translate into specific learning capabilities and active knowledge acquisition behavior at trade fairs.

\section{Multi-Group Structural Equation Modeling (SEM)}

To identify the knowledge acquisition pathways of exhibiting firms at trade fairs and how these differ according to geographical context conditions, we applied structural equation modeling (SEM). SEM is a multivariate statistical method to develop, estimate and test complex causality models that has been widely used since the $1970 \mathrm{~s}$ in behavioral and social science research (Rucker et al., 2011). The method combines factor analysis with path or multiple regression analysis (Hox/Bechger, 1998), by estimating the parameters of a pre-defined multiple-equation regression or path model, typically using maximum-likelihood procedures to optimize the model fit. To our knowledge, this method has in recent years only occasionally been applied in the context of economic geography, for instance when studying the linkages between land use and travel behavior (Van Acker et al., 2007) or the relationships between territorial knowledge characteristics and employment growth (van Oort et al., 2009).

SEM is used to postulate causality assumptions for linkages between variables that are difficult to observe or measure directly (Schumacker/Lomax, 2016; Loehlin/ Beaujean, 2017). With traditional statistical methods, such as regression analysis, surrogate indicators are commonly used to measure these latent variables in the hope to capture some of their impact on the dependent variable - but this is not always satisfactory. In contrast, SEM is a method to estimate and test causal relationships by embedding latent variables, for instance by using evaluations from an opinion survey. In contrast to conventional regression or path analysis, SEM can handle a complex set of relationships involving multiple groups of dependent variables at the same time (Bagozzi/Yi, 1988). In the context of this paper, we apply SEM by focusing on the frequency of using different knowledge acquisition pathways, which cannot be easily measured. 
We adopt SEM in the context of international trade fairs because the method allows us to use data from questionnaires to examine latent learning pathways, such as the frequency of face-to-face interaction to enquire about customer requirements or learning-by-observation techniques with respect to new technologies. SEM allows us to split up complex pathways into sub-pathways that are easier to evaluate in a survey of exhibiting firms. For instance, to determine the role of face-to-face communication at trade fairs we divided related interaction with other actors into several scenarios and prompted exhibitors to indicate the frequency of each. Specifically, we asked exhibitors to evaluate four possible scenarios of communication with customers separately: (i) customers visiting the trade fair booth take the initiative to talk to the exhibitors; (ii) exhibitors take the initiative to talk to customers at their booths; (iii) customers approach and talk to exhibitors while these are wandering around other exhibits; (iv) exhibitors take the initiative to talk to customers while visiting other exhibits. By asking about the frequency of each of these different scenarios, we were able to assign different numerical values to them that were combined into an overall value for the frequency of face-to-face communication with customers. In a similar fashion, we investigated all other pathways (also for competitors and partners) used to acquire new knowledge as shown in Figure 1. By creating quantitative evaluations of the frequency of different learning or knowledge acquisition scenarios, we generated a basis to compare the significance of these pathways.

A typical SEM procedure involves a number of consecutive stages (Schumacker/Lomax, 2016; Loehlin/Beaujean, 2017). First, an initial complete causal model with all causal links (pathways) between different levels of latent variables is constructed based on theoretical considerations. Figure 1 represents this stage of model setting in our case. Second, SEM checks whether the proposed causal links can be identified empirically (model recognition). Third, the model parameters are then estimated (model estimation) and, fourth, the initial model is adjusted to the empirical findings if necessary (model modification). In this final stage, insignificant hypothetical pathways are removed from the initial model until an acceptable level of model fit is achieved. The revised model then serves as a base model for further analyses to test deviations that occur due to the influence of moderating variables. This can be done through multi-group SEM (Schumacker/ Lomax, 2016; Loehlin/Beaujean, 2017). In the behavioral and social science literature, indicators such as gender, age or nationality are typically applied as moderating variables. In our study, geographical context variables were used. Multi-group SEM is concerned with identifying the role of moderating variables in regulating the pathways between independent and dependent variables. To accomplish this, the overall dataset is divided into several groups and the importance of pathways in the base model is examined for each group separately. From this, it is possible to identify significant differences in the importance or frequency of pathways related to the effects of the moderating variables.

\section{Empirical Research Process}

To identify learning pathways at trade fairs and their variation according to geographical context factors, we conducted an empirical study of trade fair exhibitors using a survey instrument and identified moderating variables for multi-group SEM. In the following section, we briefly discuss the empirical research process, beginning with the selection of the China International Industry Fair (CIIF) as our study case, followed by a description of the questionnaire design and survey organization and the identification of moderating variables.

\subsection{Case Selection}

We chose the trade fair business in China for our study, as the country is characterized by huge economic disparities between developed and developing cities and regions (Veeck et al., 2016). It thus represents an excellent case to investigate potential differences in knowledge acquisition according to geographical context variables.

Since the 2000 s, China's trade fair business has developed rapidly. From 2011 to 2015, the total number of trade fairs in the country increased from 6830 to 9283 , and the total economic output of trade fairs reached US- $\$ 70$ billion (Zhu/Zeng, 2017). Shanghai has become a world city (Cai/ Sit, 2005) and the undisputed leader of China's exhibition industry. With several world-scale exhibition centers, Shanghai has taken a lead over other Chinese cities. In 2018, the city had a total exhibition space of 26.7 million square meters and hosted 741 trade fairs - more than the three following cities, Beijing, Guangzhou and Zhengzhou, combined (CCPIT, 2019). Along with this growth, the city has become a key location for international flagship fairs in Asia.

To rule out specific influences of different industrial sectors in our assessment of knowledge acquisition and learning behavior, we chose the CIIF in Shanghai as our 
single study case and focused on a relatively homogenous technology field. The CIIF is a flagship manufacturing technology fair in Asia with broad Chinese and international participation, designed to mirror the global leader Hannover Messe in Germany (Bathelt/Zeng, 2014; Zhu et al., 2020). The event, which has been held every autumn in Shanghai since 1999, is co-sponsored by several departments of the Chinese central and Shanghai municipal government and generally contains five to eight sub-exhibitions. The largest and especially important sub-exhibitions of the CIIF are the Metalworking and CNC Machine Tool Show (MWCS) and the Industrial Automation Show (IAS). As a certified exhibition of the Global Association of the Exhibition Industry (UFI), the CIIF has significant international influence. In 2018, its exhibition area consisted of 280,000 square meters, attracting more than 2600 exhibitors and 180,000 visitors. Foreign exhibitors accounted for about $30 \%$ of the total number of exhibitors (CIIF, 2019).

\subsection{Questionnaire Design and Survey Organization}

Since data that links the geographical context of trade fair exhibitors with learning practices is not readily available, we organized a questionnaire survey that specifically focused on knowledge acquisition behavior. According to our conceptual model (see Figure 1), we designed a questionnaire to track the exhibitors' different knowledge acquisition activities at the event. We considered three levels that together make up the various knowledge acquisition pathways of exhibiting firms: (i) the actors with whom knowledge is exchanged (customers, competitors, partners), (ii) the way in which knowledge is exchanged (face-to-face communication, observation) and (iii) the knowledge domains of the exchange (new market trends, new technologies, new customer requirements). We split up the knowledge acquisition activities into various scenarios as indicated above and asked the respondents to indicate how often each of these scenarios occurred. This procedure provided an encompassing representation of the knowledge acquisition processes of exhibitors at the event. Following suggestions by Anderson/Gerbing (1988) and Dunn et al. (1994), we used a 7-point Likert scale and asked respondents to specify how often they would acquire knowledge during the CIIF through different scenarios on a scale from 1 (very rarely) to 7 (very frequently). We also acquired data for additional variables, such as the firm's location.

We conducted a survey every year from 2014 through 2018. According to the exhibition floor map, firms were randomly selected and visited during the event. At the exhibitor booths, we approached a representative from the middle- or top-management, who was familiar with the business situation, and asked this individual to fill out our questionnaire. While not all firms were willing to participate in our survey, $70-80 \%$ took the time to answer the questionnaire. We stayed with the respondents until they were finished answering our questions and also conducted informal interviews with them. The purpose of these interviews was to make sure that the respondents had an accurate understanding of the items in the questionnaire (Fowler/Cosenza, 2009). This also allowed us to make sure that the questionnaire was completed and to evaluate how thoroughly the questions were answered. Additionally, we were able to ask open-ended questions regarding the reasons for certain knowledge acquisition behavior. $^{2}$

Overall, we were able to distribute a total of 300 questionnaires over the years. After a thorough check, 47 questionnaires were excluded because of missing values, or when exhibitors had shown little interest and not given careful responses. Since this paper focuses on domestic exhibitors only, questionnaires from 211 Chinese firms were selected for subsequent analysis. It is usually assumed that a sample size of over 200 is sufficient to conduct SEM (Hox/Bechger, 1998). The exhibitors originated from 49 cities in China with an uneven geographical distribution. Figure 2 shows that the firms were mainly located in cities near the dominant economic centers Beijing, Shanghai, Guangzhou and Shenzhen. While our questionnaire responses also included firms from western and northeastern China, their numbers were relatively small, consistent with the geographical origins of exhibiting firms (Bathelt/Zeng, 2014). It is not surprising that those eastern coastal cities that are characterized by the highest level of economic development and innovative activities in the country were dominant in our survey. The fact that our survey was biased toward these large economic centers may in itself already be an indication that there are important differences in learning processes between different cities/regions in the country. Firms in small and medium-sized cities and in western regions may not use trade fairs as intensively as sources of knowledge to connect with markets, or may not be aware of the potential knowledge they could gain by actively participating in such events. Since most Chinese cities have sizable industries in the organizational field represented at the CIIF, the

2 These interviews were recorded digitally and later transcribed. They were used to help interpret the questionnaire results and identify underlying rationales for specific learning patterns. 


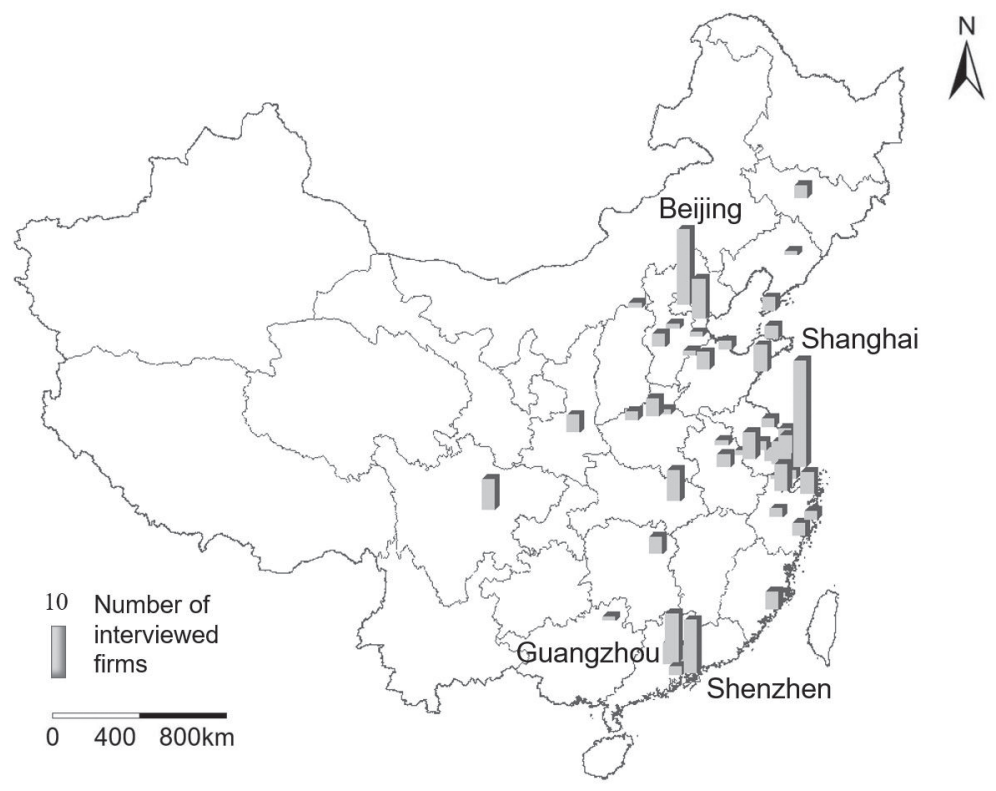

Figure 2: Geographical Distribution of Exhibitors at CIIF in Mainland China by City, 2018

uneven geographical distribution of cities in our survey may be the result of a self-selection process. ${ }^{3}$

\subsection{SEM Variable Identification}

The variables applied in our SEM procedure can be divided into two types: latent and moderating variables. The latent variables represented the knowledge acquisition pathways at trade fairs. Based on the conceptual discussion above, we distinguished the following levels of knowledge characteristics to construct these pathways: Level 1 encompassed the actors with whom knowledge is exchanged: customers (CUS), competitors (COM), partners (PAR); level 2 distinguished the ways of knowledge acquisition: faceto-face communication (F2F), observation (OBS); and level 3 differentiated the knowledge type: new market trends (MAK), new technologies (TEC), new customer requirements (REQ). Each connection between two levels related to a specific pathway in the knowledge acquisition process and represented a latent variable in our model (Hox/ Bechger, 1998). Overall, there were 6 potential pathways that connect levels 1 and 2 and another 6 pathways that connect levels 2 and 3. The maximum number of latent variables or potential pathways of knowledge acquisition was therefore 12 . We utilized the questionnaire responses

3 We did not find evidence to suggest that trade fair organizers or state organizations had any regional preferences in selecting exhibitors. provided by exhibiting firms at the CIIF to obtain data about how frequently these pathways were used. For all survey questionnaire responses, we calculated Cronbach's alpha $(0.915>0.8)$ and the Kaiser-Meyer-Olkin criterium $(0.805>0.7)$ to check whether the complex knowledge acquisition behavior can indeed be represented by few latent variables (Schumacker/Lomax, 2016; Loehlin/ Beaujean, 2017). This allowed us to conclude that the questionnaire responses were internally consistent, based on a common set of latent influences, thus justifying the application of SEM.

The second type of variables used in our model consisted of moderating variables that measured the influence of geographical context conditions in the home cities of the exhibiting firms. According to the prior conceptual discussion, these variables were grouped into four categories: (i) city scale: GDP per capita (GDP), population (POP), (ii) peripherality: western vs. coastal region ${ }^{4}$ (PERI); (iii) growth dynamics: GDP growth rate over the past 5 years (GROW); (iv) connectivity: highspeed railway (RAIL) and airport usage (AIR), measured through passenger volume. Data for the moderating variables were obtained from the China Statistical Yearbook and the China Urban Statistical Yearbook (NBSC 2018a;

4 It should be noted that this is only a rough indicator of peripherality. What is measured here is the duality between economic core cities in the coastal region and other cities in western/central China. It should also be emphasized that the corresponding exhibitors all originated from cities, not rural areas. 
NBSC 2018b). While peripherality PERI was a dummy variable (cities in western China vs. those in coastal regions), all other variables were measured on a continuous scale. For the multi-group SEM procedure applied to evaluate the impact of the moderating variables, we split up the survey responses for each context variable into two groups of cities according to high and low scores with roughly the same number of cases in each group and conducted a separate analysis.

\section{Results of the SEM Procedure}

\subsection{Base Model of Knowledge Acquisition Pathways at Trade Fairs}

Based on the conceptual diagram of knowledge acquisition pathways in Figure 1 and survey data from CIIF exhibitors regarding these latent variables, we began conducting a SEM procedure for the full model using the software package IBM SPSS AMOS 21.0. The initial procedure resulted in a significant Chi-square value for model fit (see Table 1). However, this is the expected outcome for procedures with a sufficiently large sample size even if the model does not fit the data very well (Hox/ Bechger, 1998). The latter seemed indeed to be the case, as the ratio of the Chi-square value over the degrees of freedom $\left(\chi^{2} / \mathrm{df}\right)$ in our model was larger than the conventional cut-off value of 3.0, which was reason for concern. Therefore, we modified the original model by gradually removing insignificant pathways (Schumacker/Lomax, 2016; Loehlin/Beaujean, 2017). Through this process, we removed the four pathways CUS-OBS, COM-F2F, OBS-REQ and OBS-MAK, suggesting that observation processes of customers and face-to-face interaction with competitors where relatively rare, and also that observation processes of customer requirements and market trends during the trade fairs were infrequent knowledge acquisition pathways. After this adjustment, the ratio $\chi^{2} /$ df was smaller than 3 (see Table 1) and thus deemed acceptable. Other model-fit indicators also showed an improvement and, therefore, we decided to use the modified version as our base model for further investigation.
Table 1: Model Fit Indicators of the SEM Models

\begin{tabular}{|c|c|c|c|}
\hline $\begin{array}{l}\text { Model fit } \\
\text { indicator }\end{array}$ & $\begin{array}{l}\text { Conventions to evaluate } \\
\text { model fit with continuous } \\
\text { data }\end{array}$ & Initial model & $\begin{array}{l}\text { Final (base) } \\
\text { model }\end{array}$ \\
\hline$x^{2}$ & $\begin{array}{l}\text { Significance level } \\
\left({ }^{* * *}=p<0.01\right)\end{array}$ & $1000.565^{* \star *}$ & $802.878^{\star \star *}$ \\
\hline$d f$ & The larger the better & 296 & 290 \\
\hline$x^{2} / d f$ & $\begin{array}{l}\text { Acceptable if }<3 \text {; used for } \\
\text { nested models } / \text { model } \\
\text { trimming }\end{array}$ & 3.380 & 2.768 \\
\hline AIC & $\begin{array}{l}\text { The smaller the better; used } \\
\text { for model comparisons (non } \\
\text { nested) }\end{array}$ & 1110.565 & 924.878 \\
\hline CAIC & $\begin{array}{l}\text { The smaller the better; used } \\
\text { for model comparisons (non } \\
\text { nested) }\end{array}$ & 1325.761 & 1163.550 \\
\hline ECVI & $\begin{array}{l}\text { The smaller the better; used } \\
\text { for model comparisons (non } \\
\text { nested) }\end{array}$ & 8.226 & 6.851 \\
\hline
\end{tabular}

Notes: $\mathrm{n}=211 ; \mathrm{df}=$ degrees of freedom; $\mathrm{AIC}=$ Akaike information criterion; $\mathrm{CAIC}=$ consistent $\mathrm{Akaike}$ information criterion; $E C V I=$ expected cross-validation index .

Source: Schreiber (2008)

To exclude these learning pathways from the final model seemed plausible, since the respective knowledge acquisition processes appear less typical and have not been identified as crucial in the literature (Bathelt/Zeng, 2014; Li/ Bathelt 2017). This was supported in our interviews which suggested that exhibitor contact with customers occurred mostly through face-to-face interaction, while contact with competitors was primarily based on observation processes. One exhibitor at the CIIF in 2014 emphasized that there was no direct communication with competitors: "No, we do not talk to our competitors [during the trade fair]. Yes, we know each other, we know them well, and that is [exactly] why we do not talk. Even if we wanted to talk with them, they would not [let us], they are very defensive." In other cases, interviewees suggested that communication with competitors was simply not important and that both sides focused on small talk to avoid unintended knowledge transfers. One exhibitor in 2018 explained: "This is a small field - we know each other. Sometimes we talk with them [the competitors], but we will not talk about something deep or valuable... There are too many people around you [during the trade fair], we always know what we can talk about [with the competitors] and what not." These interviews revealed the concerns of many exhibitors at the CIIF. While trade fairs are open and public events, the firms were reluctant to engage in closer relations with competitors. Analogous concerns did not exist in the communication with custom- 
ers. In fact, downstream communication is viewed as the classical raison d'être of trade fairs because direct interaction with customers provides the opportunity to create new or deepen existing market relationships.

Similarly, our interviews confirmed that knowledge about customer requirements and about market trends was not commonly gained through observation techniques. At the CIIF, the acquisition of such knowledge required direct face-to-face communication with explicit and precise information exchanges to be transferable into product adjustments and strategic reorientations later on. In contrast, learning processes through observation techniques were not significant, as the respective knowledge acquisition required two-way communication involving questions and answers. Yet, observation techniques were a common learning channel when firms wandered around other exhibits to get to know about new product or process technologies developed by their competitors (Schuldt/ Bathelt, 2011; Li/Bathelt, 2017).

Table 2 presents an overview of the SEM model estimates for the final 8 pathways of knowledge acquisition at CIIF. The model fit of the base model was acceptable (see Table 1) and all path coefficients were positive and, except for one, highly significant $(\mathrm{p}<0.01)$. The positive coefficients suggest that there is a positive association between the knowledge acquisition characteristics for each pathway. The base model was therefore used as a reference point for our investigation of the impact of the moderating variables in the next step.

Table 2: Summary of the SEM Base Model Estimates

\begin{tabular}{lllll}
\hline Pathway & $\begin{array}{l}\text { Path coefficient } \\
\text { estimate }\end{array}$ & S.E. & C.R. & p value \\
CUS-F2F & $1.003^{* \star}$ & 0.423 & 2.370 & 0.018 \\
COM-OBS & $3.548^{* \star}$ & 1.671 & 2.124 & 0.034 \\
PAR-OBS & $0.635^{* \star *}$ & 0.170 & 3.739 & 0.000 \\
PAR-F2F & $0.518^{* \star *}$ & 0.130 & 3.985 & 0.000 \\
OBS-TEC & $0.217^{* \star *}$ & 0.080 & 2.727 & 0.006 \\
F2F-TEC & $1.388^{* \star *}$ & 0.290 & 4.784 & 0.000 \\
F2F-REQ & $1.446^{* \star *}$ & 0.291 & 4.976 & 0.000 \\
F2F-MAK & $1.338^{* \star *}$ & 0.282 & 4.743 & 0.000 \\
\hline
\end{tabular}

Notes: $\mathrm{n}=211 ; \mathrm{X}^{2}=802.878^{\star \star *} ; \mathrm{df}=290 ;$ S.E. = standard error; C.R. = critical ratio; significance levels: ${ }^{* * *}=p<0.01 ;{ }^{* *}=p<0.05$.

\subsection{Influence of Geographical Factors on Knowledge Acquisition Pathways}

To measure the impact of moderating variables, we applied multi-group SEM (Schumacker/Lomax, 2016; Loehlin/ Beaujean, 2017). For each of the 6 geographical context variables identified, the survey was split up into two groups of cities with higher and lower variable scores. The test strategy was to check whether significant differences in the knowledge acquisition behavior between firms from the two groups of cities could be identified (i.e. differences in the path coefficients at a significance level of $\mathrm{p}<0.05$ ).

We started by testing the role of GDP and POP as measures of city scale and received consistent results for both variables, as illustrated in Figure 3. Firms from large and small cities showed very similar knowledge acquisition patterns. All pathways, except for one, had similar coefficients. The only significant difference between exhibitors from the two groups of cities was that observation processes of new technologies (OBS-TEC) were significantly more frequent for firms located in smaller cities compared to firms in larger cities. While interpreting this finding with care, it seems to indicate that exhibitors from smaller Chinese cities are more likely to engage in observation techniques to acquire knowledge about new technologies than exhibitors from larger cities, who may be less willing to engage in such behavior. If city size reflects technological capabilities, firms from smaller cities may be less informed about technology developments in their field and observation techniques may be more appropriate.

While more in-depth research would be necessary to verify this behavior, one could speculate that exhibitors from larger, more developed regions have a higher level of technological capability and may be more used to dealing with partners and customers at their level of sophistication. Their willingness to inspect the technologies of other exhibitors may thus be lower, as they are already aware of such technologies. We found evidence to support this in our interviews. One CIIF exhibitor with strong research capacity from Shanghai, a large city, for example explained in 2016: "No, we do not need to observe new technologies of [other attendees]. We have already the most advanced technology in this field... We conduct $R \& D$ by ourselves and do not learn from them. Maybe they want to learn from us [instead]. ${ }^{n 5}$ The reverse argument may be true for exhibitors from smaller, less developed cities with lower technological capabilities. They may use international trade fairs

5 Such a response may simply reflect an attitude of arrogance or ignorance or it may be a reflection of other capabilities firms have developed within their day-to-day context. 


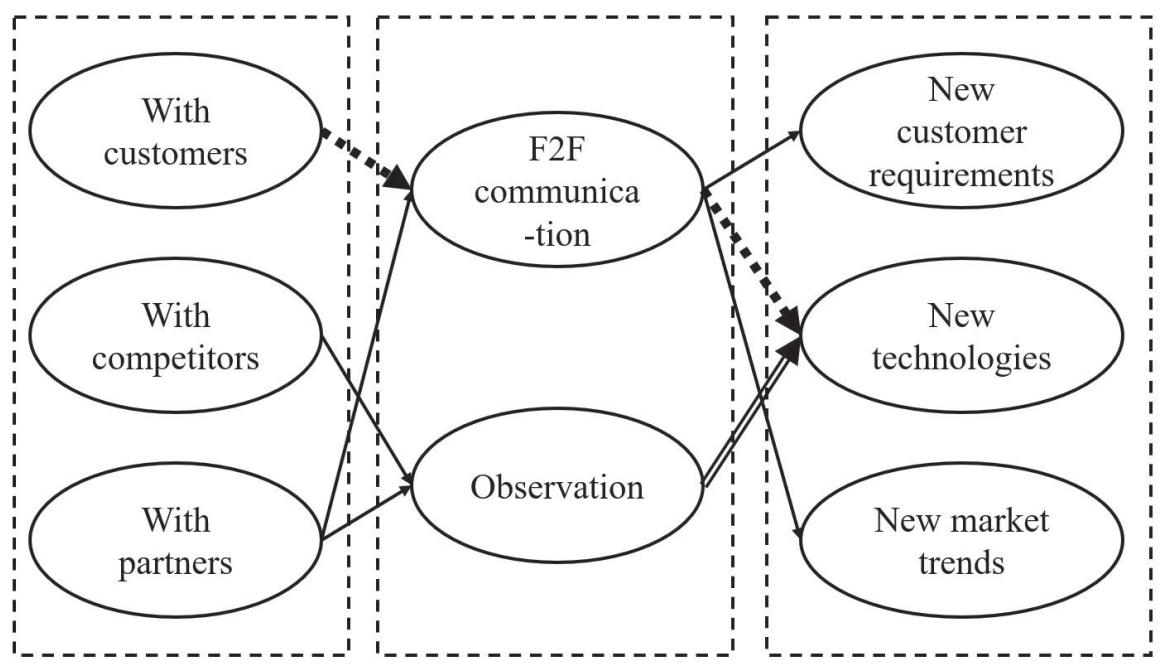

Figure 3: Differences in SEM Pathways of Knowledge Acquisition at Trade Fairs

Notes: Normal arrows indicate that there are no significant differences in knowledge acquisition pathways between the exhibitors from different groups of cities (significance level: $p<0.05$ ). Double-lined arrows indicate learning pathways that are significantly more frequent for exhibitors from smaller cities and for exhibitors from cities with poorer airport connectivity. Bold dotted arrows indicate pathways that are significantly more frequent for exhibitors from cities with better airport connectivity.

as an opportunity to specifically observe and inspect new technologies that are on display. One such exhibitor from Jiaxing, a smaller city, emphasized in 2014 that "of course, there will be a lot of time during the trade fair and we ... walk around other booths to observe new developments of technologies ... because we are from a smaller city. [The large firms from other places] do not need to [observe as much as we], but we benefit a lot from observation."

As mentioned above, we must be careful in interpreting these results, which are derived from a limited sample at a single, albeit very important, event. We also did not find similar, significant differences when comparing knowledge acquisition pathways between exhibitors (a) from peripheral and core cities, (b) from cities with faster and slower growth dynamics, and (c) from cities with better and poorer railway connectivity.

However, interesting differences resulted when we compared the learning behavior of exhibiting firms from cities with better and poorer airport connectivity. While, again, most learning pathways had similar path coefficients across all groups (see Figure 3), we found some notable deviations. Firms from cities with poorer airport connectivity used observation techniques of other exhibits significantly more often to access knowledge about new technologies, compared to firms from cities with better airport connectivity. These results correspond with the findings for smaller, less developed cities and suggest that firms from disadvantaged geographical contexts may use trade fairs actively to trigger technological catch-up processes. One exhibitor from Dezhou, a smaller and less connected city, pointed out in 2014: "Attending CIIF is very crucial for us. We have some opportunity [to follow the technological development] in our city, but it is far less effective than attending an international trade fair". Firms from cities with poorer connections may benefit particularly from the opportunities at leading flagship fairs, as they have less contact in their everyday interactions with exhibitors from distant places and from abroad that may be technologically more advanced.

Supplementary to these results, we found that exhibitors from cities with better airport connectivity engaged significantly more frequently in face-to-face communication with customers and used this method of communication more often to gain knowledge about new technologies (see Figure 3). ${ }^{6}$ For instance, an exhibitor from Guangzhou, a city with high national and international airport connectivity, suggested in 2018 that "yes, we always have very good achievements in this trade fair. We can have very

6 To check for robustness, we used per-capita railway and airport passenger volumes instead of absolute passenger volumes as alternative connectivity indicators to conduct multi-group SEM. The findings for per-capita airport connectivity were the same as before (see Figure 3) with the pathways CUS-F2F and F2F-TEC having significantly larger coefficients for better-connected cities. For per-capita railway passenger volume, we did not find significant differences in path coefficients, except for the pathway PAR-F2F, which was significantly more frequently used by exhibitors from cities with better railway connectivity. Overall, these results strongly support our previous findings. 
smooth communication with customers here ... and we can always find new technologies here". This appears to be consistent with the previous findings. We could speculate that firms that have frequent contacts with customers from other cities are accustomed to communicate with distant knowledge sources. They have developed capabilities to acquire this knowledge effectively through face-to-face interaction and are able to bridge corresponding institutional differences, while firms from less connected contexts may be inexperienced in such exchanges and may not know how to extract relevant knowledge. Altogether, we may see that exhibitors from larger, more developed and better-connected cities have the capability to learn from comprehensive face-to-face communication during leading trade fairs, such as the CIIF, while they may be less willing to engage actively in observation techniques that are less rich in knowledge flows.

\section{Conclusion}

In the context of recent research on interregional economic inequality, the aim of this paper is to understand learning behavior during international trade fairs, and analyze how this behavior differs according to geographical context conditions. In our empirical study, we employed a structural equation modeling (SEM) approach, focusing on the knowledge acquisition processes of trade fairs exhibitors. While SEM is a methodology that has not been applied intensively in economic geography in recent years, our example shows that it is particularly helpful in order to generate hypotheses about significant connections between latent variables and between latent and moderating variables. In situations with complex multi-stage activities such as learning during a trade fair, SEM is better equipped than conventional regression analysis to identify multiple pathways and compare how these change under different context conditions. In attempting to build better methods (Bathelt/Li, 2020), follow-up complementary research can be initiated to confirm or revise the results gained, perhaps by carefully applying qualitative case studies in combination with SEM.

At the CIIF in Shanghai - a leading annual manufacturing fair in Asia - we conducted a questionnaire survey of 211 exhibiting firms between 2014 and 2018 to identify the frequency of different knowledge acquisition behaviors. This was done in accordance with a model that is structured (i) around the actors with whom knowledge is exchanged, (ii) the ways of how knowledge is exchanged, and (iii) the knowledge domains of interest (see Figure
1). Having identified a base model of learning pathways through SEM, our subsequent analysis investigated how geographical context conditions related to the exhibiting firms' home locations, such as city scale, peripherality, growth dynamics and connectivity, are associated with different knowledge acquisition patterns.

In summary, we found numerous significant pathways of knowledge acquisition, confirming the findings of previous literature in the field (see Table 2 and Figure 3). Exhibiting firms communicate with customers through direct face-to-face conversation and use indirect observation techniques with competitors. Face-to-face conversations are frequent and significant for all knowledge types acquired - i.e. knowledge about new customer requirements, technologies and market trends. In contrast, indirect observation techniques of exhibitors mainly play a role in acquiring ideas about the development of new technologies. These pathways are plausible and have also been identified in qualitative studies about interactions at trade fairs.

Most of the learning pathways identified are highly significant for the exhibiting firms, regardless of their geographical context. For 5 of the 8 significant knowledge acquisition pathways in our base model, we were not able to identify systematic differences in learning patterns according to any of the moderating variables tested. While it may be tempting to conclude from this that geographical context variables do not have a very strong influence on learning pathways overall, we need to exercise care with such generalizations as we also found indication for a self-selection process - in that many exhibitors originated from larger, highly-developed cities in China's coastal region (see Figure 2). These are the cities with the highest degree of technological sophistication and firms from these cities have successfully implemented effective learning processes (Shen, 2018; Li et al., 2020). It is quite possible that we might have observed much sharper differences in learning behavior had it been possible to include more firms from more cities in central and western China. Although there is no reason to assume that similar differences in knowledge acquisition would not also occur during events in other organizational fields, more in-depth research is necessary to better understand the learning behavior of firms from other types of cities at trade fairs.

Regardless of these limitations, it is interesting to note that we were able to identify some systematic differences in knowledge acquisition behavior according to moderating context variables. We found that exhibitors from larger cities, which may on average have a stronger R\&D basis, are less inclined to use observation techniques to access knowledge about new technologies compared to firms 
from smaller cities that use these opportunities quite systematically. At the same time, we recognized that exhibitors from cities with better airport connectivity more often use face-to-face communication as a method to exchange knowledge with customers. They also acquire knowledge about new technologies more frequently through direct communication compared to firms from cities with poorer connectivity. These findings seem to underline the importance of broad geographical connectivity generating opportunities for capability-building from continuous engagement with distant knowledge sources.

The results of this study suggest that geographical context impacts a firm's capabilities and that trade fairs as temporary clusters can play different roles for different firms in their attempts to access distant knowledge. Depending on the capabilities of firms, the background of participating individuals, the efforts of trade fair organizers, as well as the geographical context conditions, these events may operate as different types of pipelines to external knowledge. To policymakers this suggests that firms from different geographical contexts may require different support policies to acquire knowledge at trade fairs and accomplish economic upgrading more effectively. Clearly, future economic development policies should pay more attention to the role of trade fairs in supporting knowledge transfers and promoting industrial innovation (Zhu et al., 2020). While the potential benefits from the rich knowledge ecologies at leading trade fairs depend on a firm's absorptive capacity and differ by organizational field, policies to support knowledge acquisition should also be differentiated by geographical context conditions, as these appear to have an impact on learning behaviors.

Acknowledgements: Parts of this paper, to which all authors contributed equally, were presented at the 2018 Global Conference on Economic Geography in Cologne and the 2019 Annual Meetings of the American Association of Geographers in Washington, DC. We would like to thank the participants of these meetings, as well as Sebastian Henn, Pengfei Li, Nicole Morar and the Reviewers for helpful comments and suggestions. Financial support for this research was provided by the China Postdoctoral Science Foundation (2018M641963), the Fundamental Research Funds for Central Universities in China (2018ECNU-HWFW002), the Zijiang Visiting Professor at East China Normal University in Shanghai, and the Canada Research Chair in Innovation and Governance at the University of Toronto.

Funding: Funder Name: Canada Research Chair in Innovation and Governance at the University of Toronto;
Funder Name: Zijiang Visiting Professor at the Institute of Urban Development, East China Normal University; Funder Name: Fundamental Research Funds for Central Universities in China; Funder Name: China Postdoctoral Science Foundation, Funder Id: http://dx.doi. org/10.13039/501100002858, Grant number: 2018M641963

\section{References}

Amin, A./Cohendet, P. (2004): Architectures of Knowledge: Firms, Capabilities, and Communities. Oxford, New York: Oxford University Press.

Anderson, J.C./Gerbing, D.W. (1988): Structural equation modeling in practice: A review and recommended two-step approach. In: Psychological Bulletin, 103(3), 411-423.

Bagozzi, R.P./Yi, Y. (1988): On the evaluation of structural equation models. In: Journal of the Academy of Marketing Science, 16(1), 74-94.

Bathelt, H./Gibson, R. (2015): Learning in 'organized anarchies': The nature of technological search processes and knowledge flows at international trade fairs. In: Regional Studies, 49(6), 985-1002.

Bathelt, H./Glückler, J. (2011): The Relational Economy: Geographies of Knowing and Learning. Oxford: Oxford University Press.

Bathelt, H./Li, P. (2020): Building better methods in economic geography. Zeitschrift für Wirtschaftsgeographie, 64(3), 103-108

Bathelt, H./Li, P./Zeng, G. (2015): Towards temporary knowledge ecologies in the Asia-Pacific region: A synthesis. In: Bathelt, H./Zeng, G. (Eds.): Temporary Knowledge Ecologies: The Rise of Trade Fairs in the Asia-Pacific Region. Cheltenham, Northampton, MA: Edward Elgar, 293-309.

Bathelt, H./Li, P./Zhu, Y.-w. (2017): Geographies of temporary markets: An anatomy of the Canton Fair. In: European Planning Studies, 25(9), 1497-1515.

Bathelt, H./Zeng, G. (2014): The development of trade fair ecologies in China: Case studies from Chengdu and Shanghai. In: Environment and Planning A, 46(3), 511-530.

Borghini, S./Golfetto, F./Rinallo, D. (2006): Ongoing search among industrial buyers. In: Journal of Business Research, 59(10), 1151-1159.

Borghini, S./Golfetto, F./Rinallo, D. (2014): Using Anthropological Methods to Study Industrial Marketing and Purchasing: An Exploration of Professional Trade Shows. SPACES online, 2014-02. Toronto, Heidelberg: www.spaces-online.com.

Cai, J./Sit, V.F. (2005): Measuring world city formation - The case of Shanghai. In: Richardson, H.W./Bae, C.C. (Eds.): Globalization and Urban Development. Berlin, Heidelberg: Springer, 239-250.

Callon, M. (2017): Markets, marketization and innovation. In: Bathelt, H./Cohendet, P./Henn, S./Simon, L. (Eds.): The Elgar Companion to Innovation and Knowledge Creation. Cheltenham, Northampton, MA: Edward Elgar, 589-609.

CCPIT - China Council for the Promotion of International Trade (2019): 2018 Annual Report of China's Exhibition Industry. Beijing: CCPIT. 
CIIF - China International Industry Fair (2019): Brief Introduction of China International Industry Fair. Online. Available HTTP: <http://www.ciif-expo.com/plus/list.php?tid=6> (May 6, 2019).

Cohen, W.M./Levinthal, D.A. (1990): Absorptive capacity: A new perspective on learning and innovation. In: Administrative Science Quarterly, 35(1), 128-152.

Dannenberg, P./Braun, B./Fuchs, M./Revilla Diez, J. (2018): Dynamics in an unequal world. In: Zeitschrift für Wirtschaftsgeographie, 62(2), 87-91.

DiMaggio, P.J./Powell, W.W. (1983): The iron cage revisited: Institutional isomorphism and collective rationality in organizational fields. In: American Sociological Review, 48(2), 147-160.

Dunn, S.C./Seaker, R.F./Waller, M.A. (1994): Latent variables in business logistics research: Scale development and validation. In: Journal of Business Logistics, 15(2), 145-172.

Entwistle, J./Rocamora, A. (2006): The field of fashion materialized: A study of London Fashion Week. In: Sociology, 40(4), 735-751.

Fowler, F.J./Cosenza, C. (2009): Design and evaluation of survey questions. In: Bickman, L./Rog, D.J. (Eds.): The Sage Handbook of Applied Social Research Methods. Thousand Oaks, CA: Sage, 375-412.

Gibson, R. (2018), Dynamic Capitalisms? Understanding Patterns of Technological Specialization through an Exploration of Interfirm Interaction at International Trade Fairs, Ph.D. thesis, Toronto: University of Toronto.

Glückler, J. (2013): Knowledge, networks and space: Connectivity and the problem of non-interactive learning. In: Regional Studies, 47(6), 880-894.

Golfetto, F./Rinallo, D. (2015): The evolution of trade show systems: Lessons from Europe. In: Bathelt, H./Zeng, G. (Eds.): Temporary Knowledge Ecologies: The Rise of Trade Fairs in the AsiaPacific Region. Cheltenham, Northampton, MA: Edward Elgar, 93-112.

Henn, S. (2012): Transnational entrepreneurs, global pipelines and shifting production patterns: The example of the Palanpuris in the diamond sector. In: Geoforum, 43, 497-506.

Henn, S./Bathelt, H. (2015): Knowledge generation and field reproduction in temporary clusters and the role of business conferences. In: Geoforum, 58, 104-113.

Hox, J.J./Bechger, T.M. (1998): An introduction to structural equation modeling. In: Family Science Review, 11, 354-373.

Jin, X./Weber, K./Bauer, T. (2010): The state of the exhibition industry in China. In: Journal of Convention and Event Tourism, 11(1), 2-17.

Kay, A.L.K. (2005): China's convention and exhibition center boom. In: Journal of Convention and Event Tourism, 7(1), 5-22.

Kirchgeorg, M./Dornscheidt, W.M./Giese, W./Stoeck, N. (Eds.) (2003): Handbuch Messemanagement: Planung, Durchführung und Kontrolle von Messen, Kongressen und Events (Handbook of Trade Show Management: Planning, Execution and Control of Trade Shows, Conventions and Events). Wiesbaden: Gabler.

Li, H./Wei, Y.D./Swerts, E. (2020): Spatial inequality in the city-regions in the Yangtze River Valley, China. In: Urban Studies, 57(3), 672-689.

Li, P. (2014): Global temporary networks of clusters: Structures and dynamics of trade fairs in Asian economies. In: Journal of Economic Geography, 14(5), 995-1021.

Li, P. (2015): Temporary clustering in developing economies: Trade fairs in South and Southeast Asia. In: Bathelt, H./Zeng, G.
(Eds.): Temporary Knowledge Ecologies: The Rise of Trade Fairs in the Asia-Pacific Region. Cheltenham, Northampton, MA: Edward Elgar, 42-66.

Li, P. (2017): Horizontal learning. In: Bathelt, H./Cohendet, P./Henn, S./Simon, L. (Eds): The Elgar Companion to Innovation and Knowledge Creation. Cheltenham, Northampton, MA: Edward Elgar Publishing, 392-404.

Li, P./Bathelt, H. (2017): From temporary market to temporary cluster: Evolution of the Canton Fair. In: Area Development and Policy, 2(2), 154-172.

Loehlin, J.C./Beaujean, A.A. (2017): Latent Variable Models: An Introduction to Factor, Path and Structural Equation Analysis. New York: Routledge.

Luo, Q./Zhong, D. (2016): Knowledge diffusion at business events: A case study. In: International Journal of Hospitality Management, 55(May), 132-141.

Maskell, P./Bathelt, H./Malmberg, A. (2006): Building global knowledge pipelines: The role of temporary clusters. In: European Planning Studies, 14(8), 997-1013.

NBSC - National Bureau of Statistics of China (2018a): China Urban Statistical Yearbook 2017. Beijing: China Statistics Press.

NBSC - National Bureau of Statistics of China (2018b): Statistical Yearbook of China 2017. Online. Available HTTP: <http://www. stats.gov.cn/tjsj/ndsj/2017/indexch.htm>(June 2, 2019).

Rinallo, D./Golfetto, F. (2011): Exploring the knowledge strategies of temporary cluster organizers: A longitudinal study of the EU fabric industry trade shows (1986-2006). In: Economic Geography, 87(4), 453-476.

Rucker, D.D./Preacher, K.J./Tormala, Z.L./Petty, R.E. (2011): Mediation analysis in social psychology: Current practices and new recommendations. In: Social and Personality Psychology Compass, 5(6), 359-371.

Schreiber, J.B. (2008): Core reporting practices in structural equation modeling. In: Research in Social and Administrative Pharmacy, 4(2), 83-97.

Schuldt, N./Bathelt, H. (2011): International trade fairs and global buzz. Part II: Practices of global buzz. In: European Planning Studies, 19(1), 1-22.

Schumacker, R.E,/Lomax, R.G. (2016): A Beginners Guide to Structural Equation Modeling. Hillsdale, 4th edn., New York: Routledge.

Shan, S./Zeng, G./Zhu, Y.-w. (2014): Role of exhibitions in the path toward technological innovation: The case of China International Industry Fair. In: Resource Development and Market, 30(7), 843-846 (in Chinese).

Shen, J. (2018): Urbanization, Regional Development and Governance in China. London, New York: Routledge.

Song, M./Berends, H./Van der Bij, H. (2007): The effect of IT and co-location on knowledge dissemination. In: Journal of Product Innovation Management, 24(1), 52-68.

Storper, M. (2009): Regional context and global trade. In: Economic Geography, 85(1), 1-21.

Storper, M./Kemeny, T./Makarem, N./Osman, T. (2015): The Rise and Fall of Urban Economies: Lessons from San Francisco and Los Angeles. Stanford: Stanford University Press.

Storper, M./Venables, A.J. (2004): Buzz: Face-to-face contact and the urban economy. In: Journal of Economic Geography, 4(4), 351-370.

Van Acker, V./Witlox, F./Van Wee, B. (2007): The effects of the land use system on travel behavior: A structural equation modeling 
approach. In: Transportation Planning and Technology, 30(4), 331-353.

Van Oort, F.G./Oud, J.H.L./Raspe, O. (2009): The urban knowledge economy and employment growth: A spatial structural equation modeling approach. In: Annals of Regional Science, 43(4), 859-877.

Veeck, G./Pannell, C.W./Smith, C.J./Huang, Y./Bao, S. (Eds.) (2016): China's Geography: Globalization and the Dynamics of Political, Economic and Social Change. 3rd edn., London: Rowman and Littlefield Publishers.

Walther, J.B./Loh, T./Granka, L. (2005): Let me count the ways: The interchange of verbal and nonverbal cues in computermediated and face-to-face affinity. In: Journal of Language and Social Psychology, 24(1), 36-65.
Wang, F.-l./Zeng, G. (2017): Analysis of city network based on innovation cooperation: Case study of Yangtze River Economic Belt. In: Resources and Environment in the Yangtze Basin, (6), 3-11 (in Chinese).

Zhong, D./Luo, Q. (2018): Knowledge diffusion at business events: The mechanism. In: International Journal of Hospitality Management, 71(April), 11-119.

Zhu, Y.-w./Zeng, G. (2017): Learning and innovation process of attendees in international trade fairs: A case study of China International Industry Fair. In: Tourism Science, 31(2), 82-94 (in Chinese).

Zhu, Y.-w./Bathelt, H./Zeng, G. (2020): Are trade fairs relevant for local innovation knowledge networks? Evidence from Shanghai equipment manufacturing. In: Regional Studies, 54, forthcoming. DOI: 10.1080/00343404.2019.1695046. 